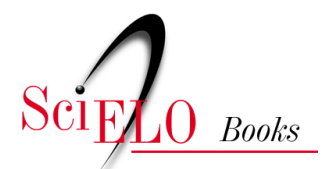

\title{
Teorías de la Emancipación y Práctica Teórica. Debates Contemporáneos
}

\author{
José Enrique Juncosa Blasco \\ Luis Fernando Garcés Velásquez
}

\section{SciELO Books / SciELO Livros / SciELO Libros}

JUNCOSA BLASCO, J. E., and GARCÉS VELÁSQUEZ, L. F. Teorías de la Emancipación y Práctica Teórica. Debates Contemporáneos. In: ¿Qué es la teoría? Enfoques, usos y debates en torno al pensamiento teórico [online]. Quito: Editorial Abya-Yala, 2020, pp. 229-255. ISBN: 978-9978-10-543-6. http://doi.org/10.7476/9789978105788.0005.

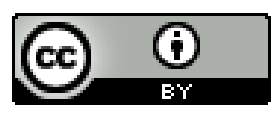

All the contents of this work, except where otherwise noted, is licensed under a Creative Commons Attribution 4.0 International license.

Todo o conteúdo deste trabalho, exceto quando houver ressalva, é publicado sob a licença Creative Commons Atribição 4.0.

Todo el contenido de esta obra, excepto donde se indique lo contrario, está bajo licencia de la licencia Creative Commons Reconocimento 4.0. 


\section{Capítulo IV TEORÍAS DE LA EMANCIPACIÓN Y PRÁCTICA TEÓRICA. DEBATES CONTEMPORÁNEOS}

\section{Sobre la necesidad de una teoría emancipatoria}

La primera pregunta que debemos hacernos es si hay necesidad o no de una teoría de la emancipación en los discursos contemporáneos. ¿Es necesaria una nueva teoría de la emancipación? ¿Acaso los distintos desarrollos del marxismo no nos habían ya proporcionado una sólida teoría de la emancipación? ¿Acaso la teoría crítica de Max Horkheimer no había afinado la propuesta marxista? (1937). En definitiva, ¿por qué es necesaria una teoría de la emancipación hoy? ¿Por qué sentimos que es insuficiente hoy una teoría emancipatoria como la formulada en el siglo pasado? ¿Qué ha cambiado?

Probablemente se trata de un cambio en el paradigma interpretativo del conjunto de las ciencias en general (Kuhn, 1962) y de las ciencias sociales, en particular. Ese cambio - proponemos- tiene que ver con la instalación del horizonte de la diversidad y la crítica a los metarrelatos o teorías totalizantes. ¿Qué quiere decir esto? Que por mucho tiempo la manera de hacer teoría se basó en una serie de supuestos heredados de la concepción moderna del mundo; a partir de ella se instaló un horizonte de seguridad en grandes "verdades" esenciales. A partir de la década del 70 del siglo pasado, ese 
horizonte comenzó a fraccionarse debido a la instalación de debates posmodernos y poscoloniales (Garcés, 2009).

La posmodernidad se ha manifestado de distintas maneras y en distintos ámbitos. Se podría decir que, en lo fundamental, cuestionó varios de los pilares en los que se sustentaba y se sustenta el pensamiento moderno: binarismo excluyente, metarrelatos fundacionales (cristianismo, marxismo, liberalismo), negación de diversidad, entronización de un solo sujeto de emancipación, etc. (Lyotard, 1990; Vattimo, 2000).52 Sin embargo, estas críticas llevaron a un relativismo absoluto que diluyó todo compromiso emancipatorio. Ello, además de constituirse en una crítica eurocéntrica al pensamiento eurocéntrico de la modernidad (Jameson, 1984; Garcés, 2009), asunto sobre el que volveremos en breve.

La teoría poscolonial, por su parte, estableció una poderosa crítica al modelo eurocéntrico y colonial de conocimiento, es decir, puso en duda la validez universal de un conocimiento que en realidad ha sido construido desde y para una espacialidad concreta: el mundo europeo, del cual derivan todas o la mayoría de las ciencias sociales (Wallerstein, 1996). En este sentido, se trata de un conocimiento provincial con pretensiones de universalidad (Chakrabarty, 2001). El planteamiento según el cual lo post- no se trata de un asunto temporal, sino de una condición que cruza el espectro de las

52 Esta suerte de esquematización de la modernidad hace referencia a la dimensión emancipatoria que habría tenido y que, según Dussel (2000), constituye su cara oculta ya que niega el rol victimario que tuvo sobre las poblaciones de América desde el momento de la conquista. Esta mirada, sin embargo, no debe llevar a negar la diversidad de formas que esta ha asumido a lo largo de la historia. Así, a manera de ejemplos podemos decir que para Habermas la modernidad se trata de un proyecto inacabado (1998); Appadurai la piensa en términos de desbordamiento (1996), y para Santos se trata de un proyecto amplio y contradictorio que se ha movido permanentemente entre emancipación y regulación (1995). 


\section{1}

prácticas sociales (Hulme, 1996; Garcés, 2009), ha permitido a la teoría poscolonial ayudarnos a mirar el lugar que ocupa la diversidad subalternizada en las poscolonias (Rivera y Barragán, 1997).

Un paréntesis explicativo: el término subalternidad, de uso recurrente en la teoría poscolonial, pretende responder a una concepción mucho más amplia y productiva que la reducida concepción de proletariado instalada por el marxismo. Subalternidad busca dar cuenta de una situación de dominación en términos no solo de clase sino de género, generación, casta, raza, etnia, etc. (Guha, 1997a; $1997 b$ ). Se trata de una posición en la escala de poder que, sin embargo, no es estática sino relacional y relativa (Coronil, 2000): relacional en el sentido de que no se ocupa de manera definitiva y esencial la posición de dominador o dominado, sino en el marco de las relaciones que configuran tal cualidad. Y por ello mismo se trata de una posición también relativa.

\section{La crítica moderno-colonial}

En el contexto latinoamericano estos dos horizontes críticos, tanto a la modernidad como a la colonialidad, han confluido en uno solo: el de las teorías de la modernidad-colonialidad llevadas adelante, entre otros, por Mignolo (2005), Escobar (2007), Walsh (2005, 2007). ¿En qué consiste esto? En no separar los dos ámbitos; es decir, hacer visible que la modernidad es inseparable de la colonialidad; la modernidad se inauguró con la conquista de América (Dussel, 2000) y, por lo tanto, se vuelve inseparable de una construcción moderno-colonial.

Uno de los elementos claves de esta postura decolonial es la crítica al eurocentrismo, a aquella construcción histórica según la cual Europa se habría convertido en el centro de la historia mundial 


\section{2}

gracias a sus cualidades intrínsecas. Uno de los aportes fundamentales de Dussel será justamente exponer el hecho que, antes de 1492, lo que existía en el mundo eran sistemas interregionales en los que la Europa central, que después — hacia el siglo XVIII — se volverá hegemónica, no era otra cosa que el lugar más periférico del sistema regional más importante del momento (1998). Se ha dado, entonces, una construcción eurocéntrica del conocimiento que niega la colonialidad como elemento constitutivo e indisociable de las sociedades. Y se ha universalizado ideológicamente una mirada provinciana, parroquialista de la modernidad: la europea. De tal manera que el eurocentrismo es la pretensión de universalidad del conocimiento europeo, gracias a privilegios epistémicos y ontológicos (CastroGómez, 2019). Esta pretensión de universalidad (más precisamente universalismo) vino acompañada de la imposición de lo europeo como algo universal que debe ser adoptado por todos.

Gracias al eurocentrismo, la colonialidad no funcionó únicamente en el nivel institucional (el de la Colonia histórica), sino también a nivel epistémico, de modo que podemos hablar de una colonialidad epistémica. Desde esta perspectiva los desarrollos teóricos de la academia del norte se han desplegado desde la condición blanca, macha, rica; es el lugar desde donde se pretende haber producido verdadero conocimiento y teoría. Bajo el discurso de neutralidad, la academia ha pretendido que la teorización no tiene vínculos con la condición económica, sexual, racial, etc. Como veremos, el lugar desde donde se siente, se piensa, se habla, se escribe es parte fundamental de lo sentido, pensado, hablado, escrito. Sin embargo, debe ser claro que cuando hablamos de lugar no nos referimos a un lugar físico, sino social, cultural, político, como veremos en breve.

Por otro lado, el riesgo de depositar toda la cualidad teorizadora en el lugar del teorizador es que, en nombre de un pretendido 
universalismo eurocéntrico, se busque plantear una teoría "otra", es decir, una teoría que en su radicalidad considere estar ubicada en el fuera de la modernidad, tal como de alguna manera puede ser planteada por actores subalternizados del tipo indígenas, mujeres, afros, etc. Se trata de una posición que hace alusión a lo que Spivak (1997) llama esencialismo estratégico, es decir, un esencialismo de tipo político que permite a los subalternos posicionarse ante el poder.

El planteamiento de Castro-Gómez (2019) y de Mary Louise Pratt (2010) en este sentido es claro: ellos plantean que, antes que pretender ubicarse por fuera de la modernidad, se trata de atravesarla, no de rodearla o negarla. En efecto, Pratt propone: "Para los estudiosos modernos de la neocolonia, la descolonización exige que no pasemos alrededor sino a través de los discursos de la metrópoli y su producción de sujetos" (p. 421). Es decir, "El camino hacia la descolonización y la toma de conciencia no pasa alrededor sino a través de los códigos de la modernidad" ( $\mathrm{p}, 418)$.

Castro-Gómez (2019), por su parte, se pregunta en qué podría consistir un proyecto no antimoderno sino transmoderno. Se trataría del modo en que el proceso mundial de modernización económica, política y cultural puede ser asimilado dialécticamente desde las distintas culturas subalternizadas por la colonización europea.

Significa atravesar la modernidad pero desde "otro lugar", precisamente desde aquellos que fueron "negados" por la modernización hegemónica euronorteamericana (posicionada como "centro" de la modernidad). En términos de Marx, la transmodernidad sería entonces la "negación de la negación", es decir, la asimilación creativa y emancipadora de la modernidad realizada desde historias locales. Se trata de una modernidad vivida desde la exterioridad relativa que niega su forma occidentalista y eurocentrada. Una modernidad, en últimas, descolonizada. Pero tal descolonización no remite, como 


\section{4}

decíamos, a un proyecto antimoderno, sino a un proceso crítico y emancipatorio frente a las instituciones desarrolladas por la modernidad misma (p. 85).

En este sentido, un proyecto transmoderno no significa el retorno a valores premodernos o precoloniales. Se trata de una asunción de doble cara:

de un lado, la modernidad eurocentrada es reinterpretada desde las historias locales negadas por la colonización; pero del otro lado, y al mismo tiempo, la propia cultura subalterna, modificada ya indefectiblemente por los procesos de modernización, debe ser reinterpretada críticamente (pp. 85-86).

Desde otro lugar reflexivo, el teórico indio Homi Bhabha plantea su crítica tanto al pensamiento dicotómico y al binarismo esencialista de la teoría moderna como al teleologismo de la izquierda clásica marxista. Para él, "No hay una verdad política o social simple que aprender, porque no hay una representación unitaria de una agencia política, ninguna jerarquía fija de valores y efectos políticos" (2002, p. 48). Por ello, apuesta por la defensa de la hibridez y el posicionamiento antiesencialista que ofrece el espacio inter-medio:

Quiero tomar posición sobre los márgenes móviles del desplazamiento cultural [...] y preguntar cuál podría ser la función de una perspectiva teórica comprometida, una vez que se toma como punto de partida paradigmático la hibridez cultural e histórica del mundo poscolonial. (p. 41)

Bhabha plantea la necesidad de explorar un Tercer Espacio como posibilidad de "eludir la política de la polaridad y emerger como los otros de nosotros mismos" (p. 59). De manera que es en el inter, en el espacio in-between que se puede lograr el sentido de la lucha cultural poscolonial (p. 59). 


\section{5}

\section{¿Quién teoriza, sobre qué y para qué?}

Lo dicho no niega que sea importante la corporeidad de quienes teorizan. La teoría no se produce en el aire sino a partir de sujetos corporizados concretos, situados territorialmente en espacios concretos con relaciones concretas. Los proclamadores de la modernidad divulgaron la ilusión de que el conocimiento es desincorporado y deslocalizado y, por lo tanto, neutral, incontaminado por las marcas sociales, raciales, coloniales, sexuales (Garcés, 2009).

Por el contrario, la teoría crítica contemporánea se esmera en plantear el lugar de enunciación desde el cual se teoriza porque, en definitiva, toda teoría funciona como un sistema de representación. En el caso de las humanidades y las ciencias sociales, hay un fuerte énfasis de representar al subalterno (Bhabha, 2002; Kozlarek, 2017).

El intelectual que representa al subalterno puede hablar por él como si fuera su apoderado o puede representarse al estilo de quien ejecuta una obra de teatro, es decir, poniéndose en escena, ex-poniéndose ante los demás, es decir, poniéndose en evidencia ante los demás. Dice Spivak que eso es lo que tiene que hacer el intelectual, exponerse ante los demás en lugar de pretender representar al subalterno (1998). De manera que el investigador y el intelectual generalmente buscan representar al otro, al subalterno, en términos de su apoderado, en términos de alguien que puede hablar en lugar del otro (vertreten). Spivak plantea que la tarea del intelectual es en realidad re-presentarse a sí mismo (darstellen), volver a presentarse ante los demás, en cuanto al lugar privilegiado que ocupa en los palacios del saber de la academia. Darstellen hace referencia justamente a la necesidad de ponerse en escena, de realizar una actuación intencional (pp. 181-183).

En esta perspectiva la pregunta importante es si aquel que representa al subalterno o pretende representarlo puede teorizar en su 


\section{6}

nombre. En las últimas décadas muchos subalternos han accedido a niveles superiores de estudios y no quieren ser representados por otros, sobre todo cuando esos otros provienen del mundo clasificatorio colonial. Ellos plantean ser la voz autorizada para hablar de sí mismos y de sus pueblos como una forma de superar el colonialismo epistémico, arrogándose la condición de condensar en sí toda la subalternidad de su grupo. En esta perspectiva, más importante que la teoría en sí misma sería quién la enuncia. Ello daría legitimidad a la teoría y tendría que ver con la incorporación de la teoría, es decir, con la capitalidad de teorizar desde la carne, la historia, la piel, la dominación.

En tal contexto debemos preguntarnos quiénes son los subalternos de carne y hueso que pueden desarrollar una reflexión teórica emancipadora. Como decíamos, todos aquellos que sufren la dominación por su condición de clase, género, raza, “anormalidad”, etc. De manera más específica podríamos decir que se condensan en los llamados nuevos movimientos sociales (Santos, 2001). En efecto, el tema del conocimiento es clave en ellos debido al contexto de producción cultural en el capitalismo posindustrial, aspecto que forma parte del orden que es necesario transformar (Juncosa, 2006, p. 85). Sin querer hacer un elenco exhaustivo, podemos aludir a los movimientos feminista, indígena, globalización alternativa, Sin Tierra, entre otros.

Por la complejidad que significa intentar lograr una perspectiva unificadora de los movimientos sociales con respecto a los aportes teóricos nos referiremos solo al movimiento feminista. En este movimiento el conocimiento, en general, y la producción teórica, de manera específica, son aspectos fundamentales. ¿Por qué? La tesis fundamental es que el conocimiento hace posible la transformación social de las relaciones de género y la construcción de sí mismas (p. 172), lo que implica una nueva manera de conocer a partir de las mujeres. 


\section{7}

En función de lo dicho, el feminismo despliega su ejercicio teórico en dos direcciones: 1 . una crítica hacia las estructuras y condicionamientos antropo y androcéntricos del ejercicio científico y epistémico; 2. una dirección propositiva de construcción de una epistemología feminista de la teoría que haga posible la transformación de las relaciones sociales en su conjunto (pp. 172-176).

\section{Lenguaje y teoría}

Una mirada menos pretenciosa del valor de la teoría de acuerdo al sujeto o lugar de enunciación tiene que ver con la enunciación misma, es decir, con el lenguaje en el que y desde el cual se teoriza. ¿Cómo se habla y se escribe de teoría? Ello depende de para quién y con quién se escribe. ¿Para los expertos? ¿Para los lectores del mundo académico? ¿Para los subalternos? La teorización sobre los subalternos se hace en un lenguaje que los subalternos no escuchan. La teórica Spivak ya citada (1998) se preguntaba si pueden hablar los subalternos; Silvia Rivera (2003, p. 56) decía que los subalternos no pueden ser escuchados por las élites dominantes. En el contexto de este capítulo podríamos decir que los académicos no pueden hablar el lenguaje del subalterno. Si uno escribe o habla para los subalternos, ¿puede escribir o hablar en su lenguaje?

"En su lenguaje" puede significar varias cosas. La más "radical" es teorizar desde una lengua minorizada, como suelen ser las lenguas indígenas. Por ejemplo, es legítimo preguntarse cómo teorizar a partir del yuyay 'pensar' y del yachay 'saber' kichwa, con la carga de racismo lingüístico heredado desde la Colonia (Garcés, 2009). Ya desde la segunda mitad del siglo XVI e inicios del XVII, se debatía si el kichwa era una lengua que servía para expresar ideas abstractas y espirituales, tal como hoy se debate si es una lengua que permite expresar los conocimientos de la modernidad $(2005,2009)$. 


\section{8}

En los debates contemporáneos sobre comunidad, comunitariedad, comunalidad, etc. (Liceaga 2013, Carrera y Solórzano 2019, Martínez 2016), podría ser útil pensar, por ejemplo, desde el minkanakuy kichwa como una forma de posibilitar un proyecto comunitario social. Minkana hace referencia a 'encargar, encomendar', mientras el sufijo -naku es un indicador de reciprocidad. De manera que minkanakuy expresa el encargarse mutuamente, el ponerse mutuamente en manos del otro/a. He aquí un ejemplo de la riqueza teórica que es posible trabajar desde/en/a partir de las lenguas minorizadas y subalternizadas por el dominio colonial. Y no solo desde una perspectiva de intercambio lingüístico, también en la propia lengua tenemos el problema de las diferencias entre el lenguaje popular-cotidiano y el lenguaje académico. Es legítimo preguntarse si se puede teorizar en el lenguaje de albañiles, montubios o vendedoras de mercado.

\section{¿Es posible interculturalizar la teoría?}

Esto nos lleva a la posibilidad de interculturalizar la teoría. Es decir, no solo incorporar lo diverso en las teorizaciones, sino que la misma teoría esté imbuida de la diversidad, que podamos asumir distintos horizontes teóricos en sus mecanismos de formulación, en sus lenguajes, en sus niveles; en definitiva, jes posible interculturalizar la teoría? Boaventura de Sousa Santos propone comprender de manera más compleja la relación entre ignorancia y conocimiento como base de posibilidad de una interculturalización de la teoría a partir de la traducción.

Dice Santos que todo acto de conocimiento se mueve en un eje que va de "A" (ignorancia) a "B" (conocimiento). En la modernidad se habrían constituido dos formas de conocimiento: el conocimiento-regulación y el conocimiento-emancipación. En el co- 


\section{9}

nocimiento-regulación el punto de ignorancia se denomina "caos", mientras el punto de saber sería "orden"; por contrapartida, en el conocimiento-emancipación el punto de ignorancia se denomina "colonialismo" y el punto de saber se designa "solidaridad".

A pesar de que estas dos formas de conocimiento están inscritas en la matriz de la modernidad eurocéntrica, la verdad reside en que el conocimiento-regulación llegó a dominar por completo el conocimiento-emancipación. Esto se debió al modo bajo el que la ciencia moderna se convirtió en conocimiento hegemónico y se institucionalizó como tal. Al dejar de lado la crítica epistemológica de la ciencia moderna, la teoría crítica, a pesar de pretender ser una forma de conocimiento-emancipación, acabó por convertirse en conocimiento-regulación. (2000, pp. 30-31)

De ahí que lo necesario hoy en día no es una nueva teoría con pretensiones de criticidad o abarcadora de todas las luchas sociales, sino una teoría de la traducción. Santos propone que no habiendo un principio único posible de transformación social, no habiendo agentes históricos de transformación únicos, no habiendo una forma única de dominación, lo que se necesita en la contemporaneidad de las luchas sociales no es tanto una teoría común, sino una teoría de la traducción que haga mutuamente inteligibles las luchas.

Nuestra posición puede resumirse del siguiente modo. En primer lugar, no hay un principio único de transformación social, e, incluso aquellos que continúan creyendo en un futuro socialista, lo ven como un futuro posible, en concurrencia con otros futuros alternativos. No hay agentes históricos únicos ni una forma única de dominación. Son múltiples las caras de la dominación y de la opresión, y muchas de ellas fueron irresponsablemente olvidadas por la teoría crítica moderna $[\ldots$.$] . En la ausencia de un principio único, no es posible reunir$ todas las resistencias y agencias bajo el amparo de una gran teoría común. Más que de una teoría común, lo que necesitamos es una 


\section{0}

teoría de traducción que haga mutuamente inteligibles las luchas y permita a los actores colectivos "conversar" sobre las opresiones a las que se resisten y las aspiraciones que los animan. (p. 28)

Así,

El conocimiento-emancipación no aspira a una gran teoría; aspira, eso sí, a una teoría de la traducción que sirva de soporte epistemológico a las prácticas emancipadoras, todas ellas finitas e incompletas y, por ello mismo, sólo sustentables cuando se organizan en red. (p. 32)

Lo dicho por Santos empata con la propuesta de Castro-Gómez (2007): hoy necesitamos, hacia dentro de la academia, de transdisciplinariedad (Garcés, 2018), y hacia fuera, de transculturalización del conocimiento. ${ }^{53}$ ¿Cómo pensar la transculturalización del conocimiento en la confrontación de conocimientos legitimados por el poder y el conocimiento cotidiano? (2019).

\section{Teorizar sobre / desde / con los no humanos}

Pero, además, el debate contemporáneo se posiciona críticamente ante el antropocentrismo que caracterizó por mucho tiempo a la modernidad. Esto ha llevado a cuestionar la clásica separación entre naturaleza y cultura (2019).

La sistematización de lo considerado "naturaleza", en términos científicos, es un proyecto nuevo que se fraguó en el siglo XVIII en el marco de los viajes realizados por científicos europeos a distintas partes del mundo (Pratt, 2010).

El conocimiento moderno estableció la distinción entre ciencias de la naturaleza y ciencias de la cultura (Eco, 1985): se considera

53 Hay varios estudios y paradigmas de pensamiento pluri, inter o transdisciplinario. Véase al apartado 4 del capítulo II. 


\section{1}

que las primeras interpretan datos, hacen interpretaciones de "primer grado"; las segundas serían interpretaciones de interpretaciones o interpretaciones de "segundo grado". La ciencia natural consistiría en interpretación de datos, trabaja con datos independientes de su observación. Las ciencias de la cultura o ciencias humanas, por el contrario, trabajan con interpretaciones de una práctica anterior, su objeto de estudio es un hecho ya interpretado.

Cuando la sociología estudia las funciones sociales, la antropología los sistemas de parentesco, la lingüística las reglas sintácticas, esas disciplinas explican el modo en que los seres humanos de determinado grupo actúan de conformidad con hábitos que son resultado de una interpretación de la realidad, aun cuando los sujetos no sean capaces de dar razón de ellos mediante interpretaciones posteriores (verbales, por ejemplo) rigurosamente organizadas (p. 263).

Lo dicho tiene relación con los debates antropológicos de las últimas décadas en las que varios autores afirman la diversidad no solo en términos culturales sino ontológicos. Es lo que se ha llamado "el giro ontológico". En términos generales, este "pretende disolver las certezas que forjó la modernidad sobre la naturaleza al juzgarlas reduccionistas, etnocéntricas, anticuadas y, hasta cierto punto, ingenuas" (Ruiz y Del Cairo, 2016, pp. 194-195). Y es que en el llamado pensamiento occidental se ha instalado la idea de "naturaleza" vinculada a miradas antropocéntricas y racionalistas; ambas permitían asumirla como un objeto a ser dominado a fin de satisfacer las necesidades humanas (2016).

La epistemología moderna ha separado el mundo de las cosas del mundo de los hombres y se ha olvidado de rastrear la agencia de los no humanos, las transformaciones que producen en los humanos (Latour, 2001). 


\section{2}

El antropólogo Philippe Descola (2012) examina la manera en que las distintas sociedades se relacionan con lo natural, problematizando así la clásica división entre naturaleza y cultura que heredó la modernidad. En sus investigaciones las distintas concepciones de lo natural conllevan distintos modos de relacionamiento con lo no humano. Una naturaleza vista como objeto, o como "exterioridad" (Santos, 2003), implica un tipo de acción sobre ella, diferente del caso en que los seres que habitan tal naturaleza son vistos como pares espirituales.

De manera complementaria, Viveiros de Castro propone, desde el perspectivismo, tomar en serio la diferente manera en que los pueblos indígenas establecen o no la distinción clásica entre naturaleza y cultura. En muchos de dichos pueblos "o mundo é habitado por diferentes espécies de sujeitos ou pessoas, humanas e não-humanas, que o apreendem segundo pontos de vista distintos" (2004, p. 225).

Como señalan Ruiz y Del Cairo:

El perspectivismo amerindio puede ser sucintamente definido como una ontología en la que el mundo es aprehendido desde diferentes puntos de vista por diferentes clases de seres — cada uno de ellos provisto de conciencia y cultura-, quienes, a su vez, se perciben a sí mismos como humanos al tiempo que definen a otros seres como no-humanos. Hace énfasis en la noción de punto de vista, esto es, un conjunto de disposiciones perceptuales y afectivas que se encuentran arraigadas o incorporadas en cada sujeto. (p. 196)

Finalmente, el antropólogo colombiano Arturo Escobar desarrolla su crítica a la manera en que se concibe la relación naturalezacultura en Occidente desde la noción colonialidad de la naturaleza (2011). Esta está marcada por las visiones mecanicistas de Occidente sobre la naturaleza. Las principales características de la colonialidad de la naturaleza son las siguientes: a) clasificación en jerarquías que 
ubica a los no-modernos, los primitivos y la naturaleza en el fondo de la escala clasificatoria; b) visiones esencialistas de naturaleza; c) subordinación del cuerpo y la naturaleza a la mente; d) visión de los productos de la tierra como subordinados al mercado impulsado por los humanos; e) ubicación de ciertas naturalezas fuera del mundo masculino eurocéntrico; f) subalternización de otras articulaciones de biología e historia a los regímenes modernos (p. 51).

Desde este posicionamiento establece el valor de lo que llama "ontologías relacionales". Se trata de ontologías

en las cuales los mundos biofísicos, humanos y supernaturales no se consideran como entidades separadas, sino que se establecen vínculos de continuidad entre estos. Es decir, en muchas sociedades no-occidentales o no-modernas, no existe la división entre naturaleza y cultura como la conocemos y, mucho menos, entre individuo y comunidad, de hecho, no existe el "individuo" sino personas en continua relación con todo el mundo humano y no-humano, y a lo largo de los tiempos. (2014, pp. 58-59)

Esta mirada propone con fuerza, entonces, el principio de relacionalidad, según el cual "todas las cosas del mundo están hechas de entidades que no pre-existen a las relaciones que las constituyen" ( $\mathrm{p}$. 58 , subrayado en el texto).

Enfatiza este autor que las ontologías no hacen alusión a simples formas representativas, sino que crean verdaderos mundos. Así, en una ontología en la que la montaña es un ser inerte, un objeto sin vida, es fácil derivar prácticas extractivistas; en una ontología en la que la montaña es un ser sintiente se seguirán prácticas de relacionamiento con ella. Lo propio puede decirse de la intersubjetividad tojolabal en la que "la milpa se pone triste" y la tierra es considerada "Nuestra Madre"; por tanto, no puede ser comercializada (Lenkersdorf, 1999, pp. 106-119). 


\section{4}

Entonces la pregunta es si es posible teorizar desde y con lo no humano. En el mundo andino pacha expresa la indisolubilidad de tiempo y espacio y pachamama da cuenta de la indisolubilidad de los seres que habitan la pacha. ¿Es posible pensar-conocer-teorizar desdecon los demás seres con los que compartimos el espacio y el tiempo?

El momento que nos ha tocado vivir, a propósito de la pandemia producida por el coronavirus, parece que nos obliga a ello. La modernidad nos había adoctrinado con la idea de que el ser humano es el centro de todo y dentro de su pensamiento se erigió la idea del valor del individuo: un sujeto dueño de su destino y de su historia. Ello nos puso a unos humanos por encima de otros humanos y no humanos, vivos y no vivos. La crisis de la covid-19 nos muestra cómo un no humano no vivo nos sometió y transformó radicalmente el mundo y las prácticas de nosotros los seres humanos y ello nos está obligando a saber, no solo si es posible pensar desde y con lo no humano, sino a hacerlo.

\section{El giro decolonial de los estudios culturales latinoamericanos y la práctica teórica}

En este apartado final retomaremos algunas afirmaciones surgidas a lo largo del libro en el marco de una reflexión disciplinaria definida por la epistemología o la filosofía de la ciencia, a fin de resignificarlas o debatirlas situándolas a la luz de lo que denominamos giro decolonial de los estudios culturales latinoamericanos, proyecto que apunta también a maneras otras de producir ciencia y trabajar con la teoría. La primera parte insiste en reiterar desde esta postura los interrogantes fundantes del pensamiento teórico; es decir, los desde dónde y para qué. Como veremos, las respuestas se agrupan en torno a la opción de pensar para vivir y son provocadas por las lecturas de Aimé Césaire ([1950] 2006), Luis Maldonado-Torres (2006) y Catherine Walsh (2013). 
La segunda parte despliega algunas características concretas de la práctica teórica desplegada en el escenario de una lucha hegemónica que disputa el marco de referencia epistémico a las imposiciones y composiciones del capitalismo tardío neoliberal y a los esquemas que, más allá del capitalismo, ahondan la crisis civilizatoria porque son insostenibles y hostiles a las trayectorias colectivas de vida. Para este apartado nos basaremos en la obra de Stuart Hall (2010) que ha contribuido a entender los estudios culturales latinoamericanos como un proyecto político que demanda nuevas formas y horizontes de práctica teórica.

\section{Del "pensar para conocer" al "pensar para vivir". La experiencia colonial como certeza colectiva del pensar}

Según Maldonado-Torres, Aimé Césaire plantea, en su "Discurso sobre el colonialismo" ([1950] 2006), una nueva ruta epistémica que consiste "en plantear que la razón es intersubjetiva y dialógica de antemano, y que la esclavitud y la colonización... representan su violación más extrema" (Maldonado-Torres, 2006, p. 187). Esa postura es fundante para el giro decolonial de los estudios culturales y traza su agenda crítica contra toda forma de pensamiento teórico, basado en el ocultamiento de la colonialidad, ya sea porque se encapsula en la certeza solipsista del sujeto o en la confianza que otorgan los automatismos metodológicos que eluden pensar desde las experiencias colectivas de sufrimiento y amenazas a la vida.

Maldonado-Torres (2006, 173 ss.), en su comentario al "Discurso sobre el colonialismo” de Aimé Césaire ([1950], 2006), cuestiona el patrón epistémico moderno colonial y señala el límite del proyecto crítico cartesiano que busca alcanzar 'claridad y distinción' a partir de la certeza que otorga el "yo pienso, luego existo". En efecto, Descartes impulsó un modelo epistémico basado en la duda metódica del sujeto, duda confinada en los márgenes de su intimidad 


\section{6}

solipsista y traducida en interrogantes a ser develados para pensar más allá de toda autoridad y doctrina, pero sin vinculación alguna con la experiencia del otro colonizado. Esa es la causa del fracaso del proyecto crítico de la empresa cartesiana que obliga a comparecer en el tribunal de la razón, fracaso extensivo también a la empresa crítica husserliana afincada en la autoevidencia de la intuición fenomenológica y, aunque parte de la experiencia del otro, de todas maneras se trata de una intuición instaurada en la subjetividad. La imposibilidad de ambos itinerarios se debe a que

mientras Descartes y Husserl intentan establecer o reformular las bases del proyecto histórico europeo a partir de la centralidad del sujeto y del valor epistemológico de la "claridad" y la "distinción" (o intuición fenomenológica en el caso de Husserl), Césaire busca introducir un nuevo tipo de razón crítica que descansa en la "claridad" que el sujeto colonizado tiene de la perversidad del proyecto civilizatorio europeo. (2006, p. 185)

Desde la lectura de la experiencia histórica de la colonialidad, el "tribunal de la razón" no radica en la subjetividad, sino en el otro colonizado que el pensamiento eurocentrado se niega y resiste a ver: los “condenados de la tierra", los damné, aquellos que son privados de ejercer un don, a quienes se les niega ofrecer lo que tienen (p. 186). Esta negación a reconocer el verdadero carácter de la civilización europea — su carácter colonial — será, a la postre, la causa del fracaso de intentos posteriores similares, incluido los de la razón posmoderna:

El "hombre europeo" se ha mantenido ciego ante la realidad del colonizado. Y por eso no ha logrado conocer más sobre sí mismo. Pero el "esclavo" ha conocido la perversidad y la inconsistencia del "amo" por siglos. Señala Césaire que los esclavos saben que los amos "mienten" (a sí mismos y a ellos) y que, al estar desapercibidos o al negarse a confrontar su mentira, son "débiles". Los esclavos y los colonizados aparecen como una fuente epistémica necesaria para 
que Europa pudiera adquirir "claridad" y "distinción" con respecto a su propia identidad y a la naturaleza de su proyecto histórico. En esto, señala Césaire en un gesto de crítica interna, los europeos traicionaron a Descartes. La mentira, más que la "claridad" y la "distinción" eran aspectos centrales del proyecto europeo [...] En vez de un proceso de duda metódica, los condenados pasaron por un proceso de sufrimiento metódico basado en la supuesta falta de humanidad de los mismos. (p. 186)

La expresión máxima del pensamiento anclado en la subjetividad individual es el proyecto cartesiano, al cual nos hemos referido en varios de los capítulos anteriores y al que uno de los autores revisados, Gilbert Ryle, cuestiona por razones diversas a la postura del giro decolonial de los estudios culturales y, como vimos, derroca su intelectualismo y el dualismo mente-cuerpo (ver capítulo III) para defender su posición de la teoría como resultado de una actividad, no de algo llamado mente. Pero Maldonado-Torres incluye otros intentos fallidos de trascender la razón moderna, como la fenomenología de Husserl y sus discípulos. De ellos, hemos mencionado, en la “Introducción”, a Levinas (2004) y a Gadamer (1983), y vale situar aquellas afirmaciones con relación al giro decolonial.

Rescatábamos de Levinas su crítica a la ciencia y al pensamiento teórico (al que considera una forma de conciencia, la conciencia teórica) porque se despliega según los mecanismos de las ciencias naturales, los cuales resultan limitados para comprender otras regiones del ser. Su crítica al pensamiento teórico, en este tramo, es ontológica, no histórica, y parte de la diversidad de las regiones del ser que no pueden ser atendidas a partir de la teoría naturalista que permea la ciencia. Pero Levinas incluye una nueva categoría en la que se muestra el ser de manera privilegiada: lo vivido, cuyo acceso no es total para la conciencia teórica. Así, "el modo de la conciencia o de la representación a través del cual entramos en contacto con el ser es 


\section{8}

un acto con una estructura determinada; es... la intuición” (2004, p. 93). La intuición posee el objeto, en tanto que la intención significativa (comprender mediante símbolos y significados) tiende a él... (p. 93 y ss.). Respecto a Gadamer, mencionábamos que la certeza fenomenológica no proviene del método sino de la autoconciencia que revelan puntos de apertura al otro (1983, pp. 37-39). La certeza es la confianza que surge de la inmediatez del propio cuerpo. Tanto Levinas como Gadamer, si bien plantean formas de conciencia individual abiertas a lo vivido, al otro desde la propia corporalidad que plantean horizontes al pensamiento más allá de los límites de la ciencia y del método, esos elementos no pasan de la experiencia subjetiva y no dejan de ser formas de conciencia individual de la experiencia vivida de la propia corporalidad que no remiten a experiencias históricas colectivas vividas por cuerpos colonizados, por los cuerpos de los esclavos y los cuerpos de las mujeres.

El giro decolonial de los estudios culturales latinoamericanos, a partir de Césaire, propone dos grandes horizontes para la práctica teórica: el horizonte crítico que identifica las formas en que la colonialidad com-pone las relaciones entre las personas, la economía, las subjetividades, la relación con la naturaleza, con el género, etc., a la vez que im-pone sus patrones; y el horizonte de disputar, reconocer y plantear nuevas formas, o formas otras de vivir juntos, decolonizantes (porque la colonialidad lo abraza todo). Como afirma Walsh,

son estos momentos complejos de hoy que provocan movimientos de teorización y reflexión, movimientos no lineales sino serpentinos, no anclados en la búsqueda o proyecto de una nueva teoría crítica o de cambio social, sino en la construcción de caminos — de estar, ser, pensar, mirar, escuchar, sentir y vivir con sentido u horizonte des(s)colonial. (2013, p.16)

Por lo tanto, el giro decolonial propone un horizonte de pensamiento marcado por lo existencial y enmarcado en un proyecto 
político que impulsa el pensar y actuar de múltiples maneras desde la opción por las existencias colectivas diferenciadas. Ese horizonte es distinto al metodológico, que conduce el pensamiento según ciertas reglas del juego de carácter lógico y procedimental; es también diverso al horizonte ontológico subjetivo, que revisamos en Levinas y Gadamer, que consiste en adecuar las formas de pensar con las distintas regiones del ser y de la subjetividad.

Desde el horizonte existencial podemos imaginar un tipo de relación distinta de la teoría con los elementos propios de la investigación en el contexto de la ciencia, como el objeto de conocimiento, el método y las técnicas. Lo usual, en la práctica tradicional de la ciencia, consiste en que la teoría preceda la metodología y esta última asume el rol de mediación entre la teoría y la identificación de técnicas, a la vez que de esclarecimiento de las implicaciones y compromisos de la teoría para con la investigación. La teoría propone un marco de trabajo investigativo (framework) que la metodología se encarga de identificar reflexivamente en función del objeto de conocimiento propuesto. Por lo tanto, la secuencia de la ciencia tradicional ordena los elementos de la investigación de la siguiente manera: objeto de conocimiento - teoría - metodología - técnicas de investigación.

Ejercer la práctica teórica desde opciones existenciales que en su diferencia confrontan la colonialidad provoca incluir nuevos elementos de la secuencia y desplazar otros para relacionarlos de distinta manera. En primer lugar, el objeto de conocimiento es desplazado a un lugar secundario y su lugar primario es sustituido por la opción existencial, pues reivindicar una existencia colectiva diferenciada se convierte en el elemento fundante de la secuencia. Este desplazamiento no es un hecho menor y evidencia dos trayectorias muy distintas para el pensamiento teórico: la de pensar para conocer y la de pensar para existir (o pensar para vivir). Así, el dinamismo de la 


\section{0}

práctica teorética se sustrae de la fuerza de gravedad de los intereses de conocimiento absorbidos por las agendas cognitivas del tipo tradiciones de investigación (Imre Lakatos) o programas de investigación (Harry Laudan) que revisamos en el capítulo III.

En segundo lugar, la opción existencial primera confiere a la metodología una mayor densidad y la ubica en un lugar intermedio entre la opción existencial y la teoría, y entre la teoría y las técnicas, porque su rol consiste tanto en clarificar las implicaciones de la opción existencial para el teorizar y el investigar, así como orientar las decisiones teóricas y las técnicas de investigación, de tal forma que no solo constituyan logros cognitivos sino prácticas transformadoras que produzcan por sí mismas reafirmaciones de las existencias colectivas. La nueva secuencia, entonces, se despliega de la siguiente manera: opción existencial - metodología - teoría - metodología - técnicas de investigación.

Finalmente, la perspectiva existencial confiere un nuevo sentido a la metodología y la integra en las pedagogías decoloniales, aquellas formas de pensar, aprendizajes, conocimientos y estrategias atesoradas por los colectivos mediante los cuales pudieron sobrevivir:

Pedagogías entendidas como las metodologías producidas en los contextos de lucha, marginación, resistencia y lo que Adolfo Albán ha llamado "re-existencia"; pedagogías como prácticas insurgentes que agrietan la modernidad colonialidad y hacen posible maneras muy otras de ser, estar, pensar, saber, sentir, existir y vivir-con. (Walsh, 2013, p. 12)

\section{"La teoría nunca será suficiente". Stuart Hall y la práctica teórica como proyecto político}

La posición del jamaiquino Stuart Hall (1932-2014) es muy importante porque tal vez se trate de la reflexión más consistente sobre la teoría desde los estudios culturales entendidos como proyecto 
político. Rastreamos algunos rasgos del teorizar en tres de sus ensayos que constan en la extensa recopilación de su producción titulada Sin garantías (2010) ${ }^{54}$, y enumeramos puntualmente aquellos que nos permiten dialogar y debatir con algunas afirmaciones de los capítulos anteriores.

Hall inscribe la práctica teórica como forma de intervención en el campo de la cultura donde tienen lugar batallas antihegemónicas de larga duración, esto es, en el horizonte de transformaciones profundas e históricas, más allá de la coyuntura. Sus aportes son una sólida invitación a ejercer el pensamiento de manera tal que permita

entender lo que está sucediendo y, especialmente, proporcionar maneras de pensamiento, estrategias de sobrevivencia, y recursos para la resistencia a todos lo que son ahora excluidos en términos económicos, políticos y culturales, de algo que podría llamarse acceso a la cultural nacional. $(2010,28)$

Ubica el teorizar como una faz del trabajo del intelectual orgánico de inspiración gramsciana que disputa sentidos en el terreno de la cultura, campo de batalla de una lucha ideológica por la hegemonía y contra la dominación. En este campo de disputas, por un lado, la práctica teórica es una intervención que hace visibles factores estructurales hegemónicos no evidentes; por otro, alimenta entendimientos para la toma de decisiones y de acción frente a tales estructuras.

La producción teórica de alguna manera está inserta en la producción de lo popular, es una "traducción del conocimiento en la práctica de la cultura" y transcurre de forma tal que "ni el conoci-

54 Estos ensayos son los siguientes: "El surgimiento de los estudios culturales y la crisis de las humanidades" ([1990] 2010, pp. 17-28); "Estudios culturales: dos paradigmas" ([1980] 2010, pp. 29-50) y "Estudios culturales y sus legados teóricos" ([1992], pp. 51-72). 


\section{2}

miento ni la práctica [van] por separado" (Hall, 2010, p. 24). Por ello, el intelectual orgánico interviene en la cultura para convertir lo dado - el sentido común- de inconsciente en consciente al explicitar sus formas de operar al mismo tiempo que traduce ese conocimiento en prácticas que generan un nuevo sentido común, es decir, un conocimiento apropiado y asumido por lo popular, por la cultura popular, en un ciclo abierto de complejidad progresiva ( $\mathrm{p}$. 44). En otro lugar, Hall se refiere al sentido común (en el contexto de su crítica al posmodernismo) de otra manera, pero con relación a que la teoría para volverse popular debe atravesar y negociar los códigos "de las masas populares", para poder conformar posibilidades de transformación y de confrontación contra las fuerzas dominantes, aunque siempre en tensión con el sentido común y con una cierta inadecuación que empuje los cambios hacia adelante:

Para que algo se vuelva popular se necesita una lucha. Esto nunca es un proceso simple, como Gramsci nos lo recordaba. No es algo que simplemente suceda. Y esto significa que siempre debe haber una distancia entre la conciencia práctica inmediata, o el sentido común de la gente ordinaria, y aquello en que es posible que se convierta. (p. 84)

La práctica teórica así entendida se ejerce en medio de un necesario "forcejeo" —en palabras de Hall (pp. 59 ss.) — que nace de la tensión entre teoría y la práctica con algunas consecuencias que marcan las siguientes señas de identidad del teorizar según el proyecto político de los estudios culturales:

a. Los avances teóricos sin compromisos respecto a proyectos políticos no sirven. El trabajo teórico exquisito o estar en las avanzadas teóricas no salvan de la insignificancia a la hora de responder a las crisis. La pregunta crucial es si tales hallazgos teóricos metodológicos contribuyen a ganar batallas y pueden 


\section{3}

ser insertados "en una comprensión del proyecto histórico/ político más amplio que ahora confronta a la humanidad" (p. 27). La formación de conceptos y el poder de la abstracción no tienen primacía en tanto impliquen eludir la tensión entre lo teórico y lo político. "Las ganancias teóricas nunca serán suficientes" (p. 59).

b. La conexión de la práctica teórica con las emergencias sociales no disminuye el compromiso por la "la ineludible seriedad del trabajo intelectual" que impulsa "a saber más que los intelectuales tradicionales", porque se trata de trabajar en el contexto de una disputa, de una confrontación que nos exige al máximo (p. 63). En esta disputa "no puntúa” la militancia del intelectual que no se inscribe en el trabajo teórico y conceptual.

c. Las teorías que nos generan tensión son mejores que aquellas que nos ayudan a hablar cómodamente: "la única teoría que vale la pena tener es aquella con la que uno tiene que luchar, no aquella de la que uno habla con una fluidez profunda” (p. 54).

d. La práctica teórica debe tener tanta conexión con las emergencias sociales que debe ser capaz de interrumpir su camino para atender las interrupciones que patean la puerta del pensamiento para tensionar y sacudir la teoría y torcer su curso normal. Algunas emergencias sociales causan interrupciones que provocan transformaciones teóricas (p. 59) como, por ejemplo, el feminismo.

e. La práctica teórica está tensionada también por la comunicación de conocimientos, en sí misma una función intelectual distinta a lo que hoy conocemos como difusión de la ciencia, pues el intelectual orgánico "no se puede absolver de la responsabilidad de la transmisión de esas ideas, ese conocimiento, a través de la función intelectual, a quienes no pertenecen profesionalmente a la clase intelectual" (p. 56). 


\section{4}

Este primer esbozo de solo algunos rasgos de la práctica teórica, según la entiende Hall, da pie para retomar algunas posturas revisadas en el libro. Por de pronto, Hall propone la práctica teórica como algo distinto a la teoría de la práctica de Pierre Bordieu (1977) y su relectura hace posible impulsar el trabajo intelectual para "movilizar todo lo que podemos encontrar en términos de recursos intelectuales para entender qué es que sigue haciendo las vidas que vivimos, y las sociedades en que vivimos, profundamente antihumanas" (Hall, 1992, p. 17, citado en Walsh, 2013, p. 17).

Asimismo, si bien Hall se reconoce muy cercano a la escuela del pensamiento crítico de Frankfurt, revisado en el capítulo I, su crítica descentra la figura del intelectual para hacer de la teoría una suerte de traducción en categorías populares al servicio de y en dependencia respecto a las formaciones sociales en las que inscribe su trabajo intelectual. El intelectual, entonces, será un traductor que no podrá absolverse de la tarea de comunicación, lo cual constituye una novedad respecto a la teoría crítica de Frankfurt, que corre el riesgo de encapsularse en la academia y alimenta el peligro de "dar pensando", sin apuntar a la constitución de lo popular como marco de intervención y de negociación semiótica y de sentidos.

La práctica teórica de Hall obliga, por último, a repensar la noción de sentido común que revisamos en el capítulo II y que trasluce el punto de vista de la filosofía de la ciencia, según la cual la teoría sucede en un plano distinto y separado y, si, en todo caso, existen similitudes y conexiones, estas serán de carácter formal. Para Hall, en cambio, la conexión entre teoría y sentido común es mucho más rica y ambos conforman dimensiones distintas de un mismo ciclo, según el cual el sentido común es la apropiación de la teoría por los movimientos o formaciones sociales. No existe práctica teórica sin la modelación del sentido común pues se trata de conocimientos asu- 


\section{5}

midos en las prácticas sociales y que generan nuevas aproximaciones desde esas mismas prácticas.

Tal opción cambia la noción de productividad o ganancia teórica más allá de cualquier narrativa del progreso o de cualquier posición que defina el avance de la ciencia en términos de progreso conceptual, como afirmaba Laudan en el capítulo III, parar quien las credenciales de la teoría consisten en exhibir la mayor lista posible de solución de problemas mejor si son conceptuales antes que los empíricos. Para Hall la práctica teórica cierra algunos problemas, pero más que ganancias teóricas abre nuevos interrogantes y problemas. La ganancia no consiste en la capacidad de "nombrar algo nuevo que no podía decir antes... [sino] sumergirnos en nuevos problemas, nuevos forcejeos" (2010, p. 67). Esas ganancias no otorgan garantías ni seguridades y no ocurren según la lógica problema-solución (como afirma Laudan), sino según un ciclo que va "de problemática en problemática... se gana terreno, pero siempre inestable" (p. 67). 